\title{
Clinical Workup of Nodular and Mass Lesions of the Endocrine Organs
}

\author{
Xiaoqi Lin and Bing Zhu \\ Northwestern Memorial Hospital, Feinberg School of Medicine, Northwestern University
}

USA

\section{Introduction}

Fine needle aspiration (FNA) biopsy is a minimally invasive procedure that is widely used to evaluate nodular, mass, or cystic lesions of the endocrine organs, especially the thyroid glands. FNA biopsy can be performed without imaging guidance for palpable nodules or with guidance by ultrasound, computerized tomography (CT) scan, magnetic resonance imaging (MRI) scan, or endoscopic ultrasonography (EUS). FNA biopsy is used to make diagnoses of non-neoplastic lesions (infection, inflammation, and hyperplastic nodule), benign neoplasms, and malignancies. FNA biopsy is also used to distinguish primary neoplasms from metastatic malignancies. Immunohistochemical (IHC) stains and molecular assays can be performed on FNA biopsy materials, in order to make more accurate diagnoses and to determine the appropriateness of targeted treatment.

\section{Clinical workup of thyroid nodules}

\subsection{Introduction}

Thyroid nodules are a common clinical problem. Five to fifteen percentage of thyroid nodules are malignant depending on age, sex, radiation exposure history, family history, and other factors(Caruso and Mazzaferri 1991). In the United States, approximately 44,670 new cases of thyroid cancer were diagnosed and 1,690 deaths were caused by thyroid cancer in 2010(Jemal, Siegel et al. 2010). Autopsy examination showed that prevalence of micropapillary cancers was $13 \%$ in the United States(Harach, Franssila et al. 1985). The incidence of thyroid cancer is rising(Cooper, Doherty et al. 2009).

\subsection{Clinical workup of thyroid nodules}

Thyroid nodules can be detected by palpation (5\% in women and $1 \%$ in men)(Vander, Gaston et al. 1968; Tunbridge, Evered et al. 1977), and are increasingly detected by ultrasound examination (19 - 67\%)(Mazzaferri 1993; Tan and Gharib 1997) and other scanning techniques, such as fluorodeoxyglucose-positron emission tomography (18FDGPET)(Are, Hsu et al. 2007), sestamibi, CT scan, and MRI scans. Ultrasound should be performed in all patients with suspected thyroid nodules(Cooper, Doherty et al. 2009). A serum TSH level and 18FDG-PET should be obtained(Cooper, Doherty et al. 2009). The risk of malignancy in 18 FDG-PET positive nodules is about $33 \%$, and the cancers may be more aggressive(Are, Hsu et al. 2007). Therefore, these lesions require prompt evaluation. If the 
serum TSH is subnormal and diffuse or focal uptake on ${ }^{18}$ FDG-PET scan is identified, a radionuclide thyroid scan using either technetium 99mTc pertechnetate or 123I should be obtained to document whether the nodule is hyperfunctioning. No FNA evaluation is necessary(Cooper, Doherty et al. 2009). Higher serum TSH is associated with increased risk of malignancy in a thyroid nodule(Boelaert, Horacek et al. 2006) and prompts an FNA biopsy(Cooper, Doherty et al. 2009).

\subsection{Fine needle aspiration biopsy of thyroid nodules}

FNA has been demonstrated to be the most accurate and cost-effective method for evaluating thyroid nodules, which has resulted in a reduction of unnecessary thyroid surgery for patients with benign nodules and allowed appropriate triaging of patients with thyroid cancer to surgery. Before the routine use of thyroid FNA, only 14\% of surgically resected thyroid nodules were malignant(Hamberger, Gharib et al. 1982). With current thyroid FNA practice, the percentage of malignancy in resected nodules exceeds $50 \%$ (Yassa, Cibas et al. 2007). Half of the malignant nodules were diagnosed by FNA cytology as malignant, and the other half had indeterminate cytology, a term used to describe atypia of undetermined significance (AUS), follicular neoplasm, and suspicious for malignancy(Yassa, Cibas et al. 2007). The sensitivity of FNA in diagnosis of malignancy is $66 \%$ in palpable thyroid nodules(Tee, Lowe et al. 2007). However, FNA diagnostic performance has varied across different studies. Core needle biopsy has a higher adequacy rate than FNA but seems less sensitive, especially for papillary carcinoma(Renshaw and Pinnar 2007). The combination of FNA with core needle biopsy seems to have the highest adequacy rate and sensitivity(Renshaw and Pinnar 2007). Every patient with a palpable thyroid nodule is a candidate for FNA biopsy and should undergo further evaluation to determine if an FNA is warranted. Before making the decision to proceed with an FNA, a serum thyrotropin level and thyroid ultrasound should be obtained.

Generally, only nodules $>1 \mathrm{~cm}$ should be evaluated by clinical history, laboratory tests, ultrasound, and FNA, since they have a greater potential to be clinically significant cancers(Cooper, Doherty et al. 2009). Routine FNA is not recommended for nodules $<1 \mathrm{~cm}$. Occasionally, there may be nodules $<1 \mathrm{~cm}$ that require evaluation because of suspicious US findings, associated lymphadenopathy, a history of head and neck irradiation, or a history of thyroid cancer in one or more first-degree relatives(Cooper, Doherty et al. 2009). However, some nodules $<1 \mathrm{~cm}$ that lack these warning signs eventually cause morbidity and mortality(Cooper, Doherty et al. 2009). These are rare, and given unfavorable cost-benefit considerations, attempts to diagnose and treat all small thyroid cancers in an effort to prevent these rare outcomes would likely cause more harm than good(Cooper, Doherty et al. 2009). Sonographic features suspicious for malignancy include presence of microcalcifications, hypoechogenicity, increased intranodular vascularity, irregular/lobulated infiltrative margins, an absent halo, nodal metastases, and a shape taller than the width measured in the transverse dimension(Cooper, Doherty et al. 2009). Microcalcifications are highly specific for PTC, but may be difficult to distinguish from colloid.

Thyroid FNA is performed with 27, 25 or 23 gauge needles with or without imaging guidance, however most are performed under ultrasound guidance. The solid area of thyroid nodules should be biopsied. Direct smears of FNA samples are preferred and cytospin or ThinPrep can be also used. The air-dried slides are stained with modified Giemsa stain for immediate interpretation for evaluation of adequacy. Alcohol fixed slides are stained with Papanicolaou stain, which is the ideal method to evaluate nuclear features for the diagnosis of papillary thyroid carcinoma. 
Side effects of thyroid FNA include hemorrhage and infection. Acute thyroid hemorrhage may cause acute respiratory distress, which needs prompt intervention(Donatini, Masoni et al. 2010). Infarction in thyroid nodules can occur after FNA, which may interfere with histologic evaluation(Das, Janardan et al. 2009).

\subsection{The Bethesda system for reporting thyroid cytopathology}

In order for pathologists to better communicate thyroid FNA interpretations to referring physicians, the Bethesda System for Reporting Thyroid Cytopathology (TBSRTC) was developed in 2007(Cibas and Ali 2009). The 2007 National Cancer Institute (NCI) conference and 2009 35th European Congress of Cytology (ECC) reviewed and discussed 6 topics(Cibas and Ali 2009): (1) indications for thyroid FNA and pre-FNA requirements; (2) training and credentialing; (3) techniques for thyroid FNA; (4) diagnostic terminology and morphologic criteria; (5) utilization of ancillary studies in thyroid FNA; and (6) postFNA testing and treat-pre-FNA requirements, training specifications, criteria for the selection of patients to undergo FNA, diagnostic categories and criteria, ancillary testing and post-FNA follow-up and treatment options. TBSTRC classified thyroid FNA findings into 6 categories (Table 1) (Cibas and Ali 2009).

\begin{tabular}{|c|c|}
\hline Category & Subcategory \\
\hline Nondiagnostic/unsatisfactory & $\begin{array}{l}\text { Cystic fluid only, acellular/scant cellular specimen, } \\
\text { and others (obscuring blood, clotting artifact, air } \\
\text { drying artifact, poor fixation, poor preservation, etc.) }\end{array}$ \\
\hline Benign & $\begin{array}{l}\text { Consistent with a benign follicular nodule } \\
\text { (adenomatoid/hyperplastic nodules, etc.), thyroiditis } \\
\text { (lymphocytic, Hashimoto, granulomatous), and others }\end{array}$ \\
\hline $\begin{array}{l}\text { Atypia of undetermined } \\
\text { significance (AUS) or follicular } \\
\text { lesion of undetermined } \\
\text { significance (FLUS) }\end{array}$ & $\begin{array}{l}\text { Indeterminate for follicular neoplasm versus } \\
\text { adenomatoid nodule, indeterminate for papillary } \\
\text { thyroid carcinoma, suggestive of benign Hürthle cell } \\
\text { nodule or lymphocytic thyroiditis, cyst-lining cells } \\
\text { with atypia, follicular cells with nuclear enlargement } \\
\text { and prominent nucleoli in patients with a history of } \\
\text { radiation, carbimazole, or other pharmaceutical } \\
\text { agents, reparative/reactive changes, atypical } \\
\text { lymphoid infiltration, and others }\end{array}$ \\
\hline $\begin{array}{l}\text { Follicular } \\
\text { suspicious for a follicular } \\
\text { neoplasm }\end{array}$ & Specify if Hürthle cell (oncocytic) type \\
\hline Suspicious for malignancy & $\begin{array}{l}\text { Suspicious for papillary carcinoma, medullary } \\
\text { carcinoma, metastatic carcinoma, lymphoma, and } \\
\text { others }\end{array}$ \\
\hline Malignant & $\begin{array}{l}\text { Papillary thyroid carcinoma, poorly differentiated } \\
\text { carcinoma, undifferentiated (anaplastic) carcinoma, } \\
\text { medullary carcinoma, squamous cell carcinoma, } \\
\text { carcinoma with mixed features (specify), metastatic } \\
\text { carcinoma, non-Hodgkin lymphoma, and others }\end{array}$ \\
\hline
\end{tabular}

Table 1. The Bethesda system for reporting thyroid Cytopathology (TBSRTC)(Cibas and Ali 2009) 


\subsubsection{Category: Nondiagnostic/unsatisfactory}

To be satisfactory for evaluation, a specimen should contain at least 6 groups of benign follicular cells and at least 10 cells in each group(Grant, Hay et al. 1989; Haider, Rakha et al. 2011), except for findings consistent with colloid nodule(Cibas and Ali 2009). Nondiagnostic/unsatisfactory cases should account less than 10\% with a range from $2-20 \%$ of cases(Cibas and Ali 2009). Postoperative risk of malignancy in thyroid nodules with nondiagnostic cytology is $12 \%$ on average with a range from $0-32 \%$ (Cibas and Ali 2009; Wang, Friedman et al. 2010). The risk of malignancy for a cyst fluid only sample is $4 \%$ (Renshaw 2001). A repeated FNA aspiration with ultrasound guidance is recommended for nondiagnostic/unsatisfactory and clinically or sonographically worrisome cyst fluid only cases, and is diagnostic in $50-88 \%$ of cases(Renshaw 2001; Cooper, Doherty et al. 2009). Aspirates composed of pure colloid and lacking a cellular component should be considered benign rather than non-diagnostic(Layfield, Cibas et al. 2010).

\subsubsection{Category: Benign}

The FNA smears of hyperplastic/adenomatoid nodules typically show bland follicular cells as well as metaplastic Hürthle cells arranged in macrofollicles, normofollicles, and possibly microfollicles, and show moderate to abundant colloid (Figure 1). Abundant macrophages including hemosiderin-laden macrophages, proteinaceous material, hemolyzed red blood cells, reactive follicular cells, and stromal cells may be seen.

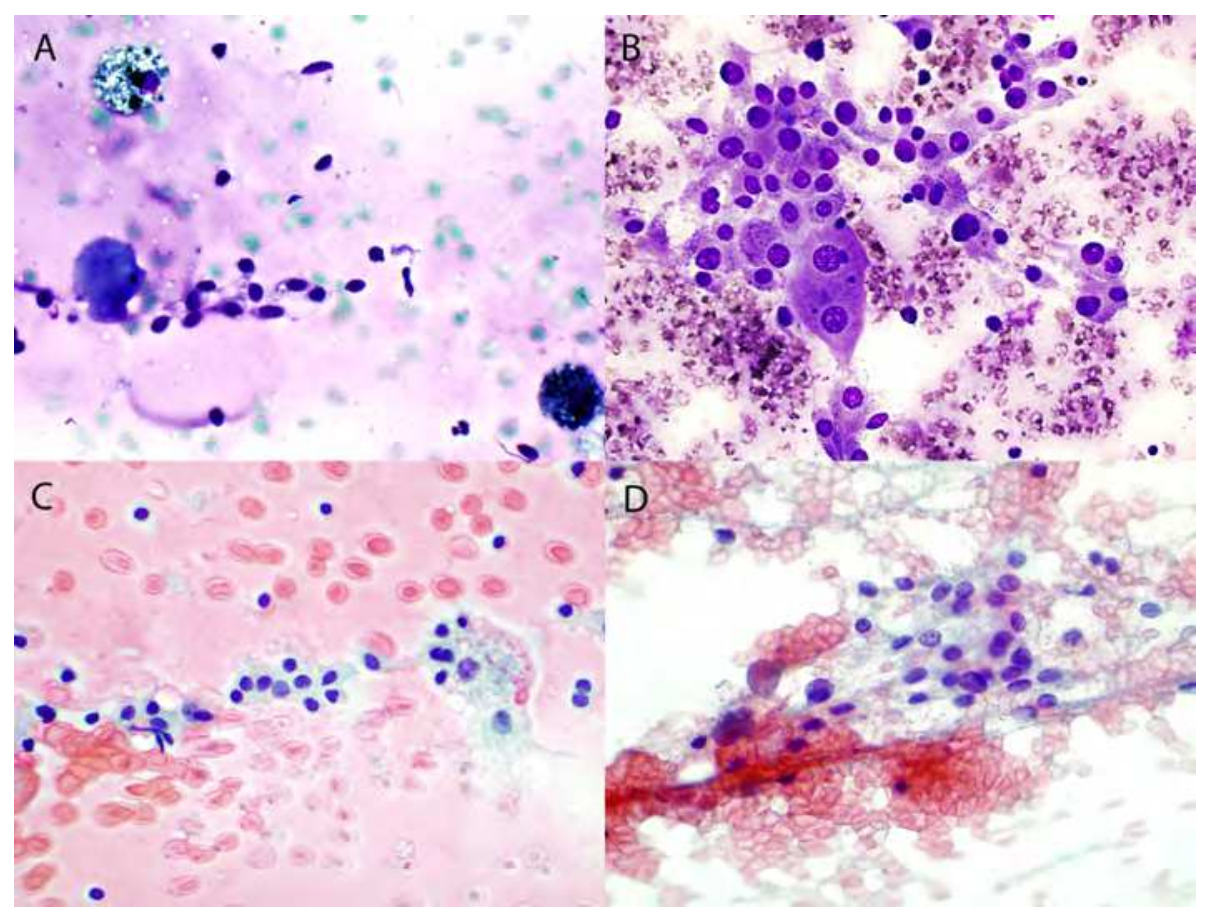

Fig. 1. Thyroid hyperplastic/adenomatoid nodule, FNA cytology, modified Giemsa (A and C) and Papanicolaou stain (B and D), 600x. Figures A and C show benign follicular cells in a background of abundant colloid with macrophages. Figures B and D show metaplastic Hürthle cells with moderate to abundant granular cytoplasm. 
The FNA smears of chronic lymphocytic thyroiditis (Hashimoto's thyroiditis) typically show metaplastic Hürthle cells and follicular cells with possible reactive atypia (nuclear pseudoinclusions, nuclear grooves, prominent nucleoli), and abundant polymorphous lymphocytes and lymphohistiocytic aggregates (germinal centers) (Figure 2).

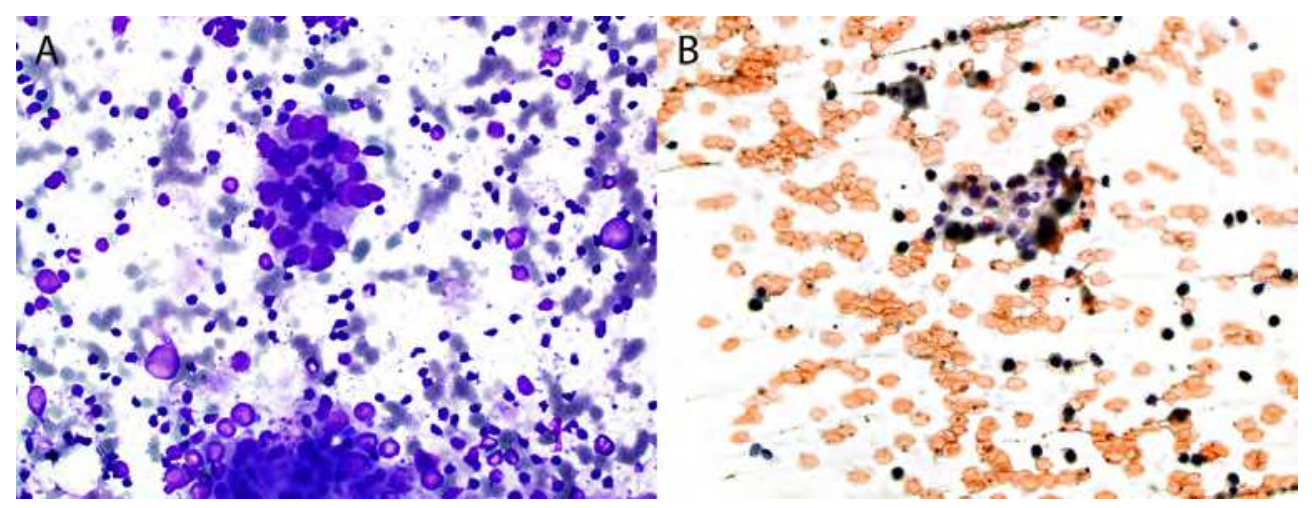

Fig. 2. Chronic lymphocytic thyroiditis, FNA cytology, modified Giemsa (A) and

Papanicolaou stain (B), 400x. FNA smears show nests of metaplastic Hürthle cells infiltrated with lymphocytes, and background of polymorphous lymphocytes and lymphohistiocytic aggregates (follicular germinal center).

FNA results with benign cytology should account for 67 - 70\% of cases(Cibas and Ali 2009). Postoperative risk of malignancy in thyroid nodules with benign cytology should be approximately 5\% with a negative predictive value (NPV) of $95 \%$ according to the 2009 American Thyroid Association (ATA) guidelines(Cooper, Doherty et al. 2009) and $0-3 \%$ according to the 2007 TBSRTC(Layfield, Cibas et al. 2010) . Other studies showed an average of $6 \%$ with a range from $1-18 \%$ (Cibas and Ali 2009; Lewis, Chang et al. 2009; Wang, Friedman et al. 2010). Further immediate diagnostic studies or treatment are not routinely required(Cooper, Doherty et al. 2009). Some authors suggested that patients be followed up with repeated assessment by palpation or ultrasound at 6- to 18-month intervals and should be followed-up for at least 3 - 5 years(Layfield, Abrams et al. 2008; Cooper, Doherty et al. $2009)$. If the nodule shows significant growth $(20 \%$ increase in nodule diameter with a minimum increase in two or more dimensions of at least $2 \mathrm{~mm}$ (Cooper, Doherty et al. 2009)) or shows "suspicious" sonographic changes, a repeated FNA is considered.

\subsubsection{Category: Atypia of undetermined significance (AUS) or follicular lesion of undetermined significance (FLUS)}

AUS/FLUS includes cases in which the cytomorphologic findings are not representative of a benign lesion such as a hyperplastic/adenomatoid nodule, yet the degree of cellular or architectural atypia is not sufficient to render an interpretation of follicular neoplasm/suspicious for a follicular neoplasm or suspicious for malignancy. This diagnosis may also be used in thyroid FNA specimens that are less than optimal due to limited cellularity, poor fixation and presence of obscuring blood. AUS cases account for $3-6 \%$ of thyroid FNAs(Yang, Schnadig et al. 2007; Yassa, Cibas et al. 2007). Postoperative risk of malignancy in nodules with atypical cytology is $16 \%$ on average with ranges from 5 - 
48\%(Cibas and Ali 2009; Wang, Friedman et al. 2010), and 5 - 15\% according to 2007 TBSRTC(Layfield, Cibas et al. 2010). Patients with AUS cytology should be managed by undergoing an iodine ${ }^{123}$ scan, especially if serum TSH level is low. If the scan is "hot", clinical follow-up with a repeated FNA in 3-6 months is recommended(Yassa, Cibas et al. 2007; Cibas and Ali 2009; Layfield, Cibas et al. 2010). Repeat FNA will result in definitive interpretation in most of cases, however a repeat diagnosis of AUS occurs in about $20 \%$ of cases(Yassa, Cibas et al. 2007). If the scan is "cold", the patient should be referred for surgery.

\subsubsection{Category: Follicular neoplasm or suspicious for a follicular neoplasm}

The category of follicular neoplasm or suspicious for a follicular neoplasm identifies a nodule that might be a follicular carcinoma (FC) and triages it for surgical lobectomy(Cibas and Ali 2009). The FNA smears are typically highly cellular, composed of abundant larger follicular cells arranged in microfollicles or trabeculae with crowding and nuclear overlapping, and have scant colloid (Figure 3)(Cibas and Ali 2009). FNA cytology cannot distinguish follicular carcinoma from benign follicular adenoma and sometimes adenomatoid nodule, because distinguishing a follicular carcinoma from follicular adenoma is based on identification of capsular invasion or vascular invasion of in the capsule. Distinguishing a follicular adenoma from adenomatoid nodule is based on the identification of entire capsulation. Diagnosis of follicular variant of papillary carcinoma is based on nuclear features, which, sometimes, is challenging.

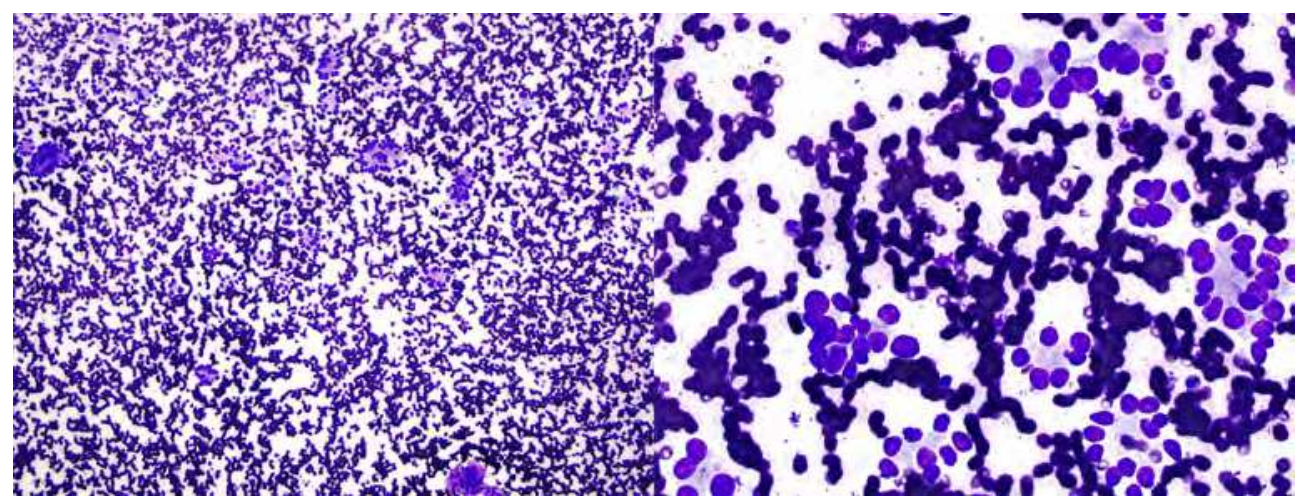

Fig. 3. Thyroid follicular lesion, FNA cytology, modified Giemsa stain, 100x (A) and 600x (B). FNA smears show abundant follicular cells arranged in microfollicles, and absence of colloid.

This category accounts for $9-30 \%$ of FNA specimens(Hegedus 2004; Mihai, Parker et al. 2009). Most cases in this category are benign follicular adenomas or adenomatoid nodules (up to 35\%)(Yang, Schnadig et al. 2007). Postoperative risk of malignancy is $25 \%$ on average with a range from 14 - 49\% (Cibas and Ali 2009; Wang, Friedman et al. 2010), and is $15-30 \%$ according to 2007 TBSRTC(Layfield, Cibas et al. 2010). Some cases are follicular carcinoma and others are follicular variant of papillary carcinoma(Yassa, Cibas et al. 2007). Hürthle cell variant should be specified due to different underlying genetics from follicular neoplasms. About $16 \%$ - 25\% cases of Hürthle cell variant in this category are proven to be hyperplastic 
proliferations of Hürthle cells in nodular goiter or lymphocytic thyroiditis(Giorgadze, Rossi et al. 2004; Pu, Yang et al. 2006). About $15 \%$ to $45 \%$ of nodules are malignant, and the remainder of the neoplasms prove to be Hürthle cell adenomas(Giorgadze, Rossi et al. 2004; $\mathrm{Pu}$, Yang et al. 2006). If the reading is "Hürthle cell neoplasm", either lobectomy/hemithyroidectomy or total thyroidectomy is recommended. When diagnosed by FNA as either Hürthle cell neoplasm or Hürthle cell lesion, males are much more likely to have malignant tumors than females( $\mathrm{Wu}$, Clouse et al. 2008).

\subsubsection{Category: Suspicious for malignancy}

The "suspicious" category is used for those cases that show some nuclear features of papillary carcinoma or other malignancies, or have scant diagnostic cells due to sampling reason or small tumor (papillary microcarcinoma), but are not enough for diagnosis of malignancy. Postoperative risk of malignancy in thyroid nodules with suspicious for malignancy is $62 \%$ on average with a range from $42-87 \%$, and is $65-75 \%$ according to 2007 TBSRTC(Layfield, Cibas et al. 2010). The rest are usually follicular adenoma(Yang, Schnadig et al. 2007; Yassa, Cibas et al. 2007; Cibas and Ali 2009; Wang, Friedman et al. 2010). Nodules called suspicious for papillary carcinoma are resected by lobectomy, near total thyroidectomy, or thyroidectomy(Cooper, Doherty et al. 2009; Layfield, Cibas et al. 2010).

\subsubsection{Category: Malignant}

The category of malignancy is used whenever the cytomorphologic features are conclusive for a malignancy. The diagnosis of papillary thyroid carcinoma by FNA biopsy depends on nuclear features of follicular cells (enlarged and elongated nuclei with nuclear pseudoinclusion, nuclear grooves, powdery chromatin), and architectures (papillary versus follicular) (Figure 4). Other FNA features include psammomatous calcification, and "gum"like thick colloid.

The characteristic FNA features of undifferentiated (anaplastic) carcinoma are presence of pleomorphic, markedly atypical spindle cells (Figure 5).

The FNA features of thyroid medullary carcinoma are presence of pleomorphic polygonal tumor cells with characteristic neuroendocrine nuclear features "(salt and pepper") and granular cytoplasm, which are present in a single cell pattern, loosely cohesive clusters, follicular and papillary architecture (Figure 6). Serum calcitonin screening is useful in detection of C-cell hyperplasia and medullary thyroid cancer.

Large cell lymphoma is the predominant subtype, and consists of relatively monotonous populations of large, abnormal lymphoid cells(Morgen, Geddie et al. 2010). Marginal zone lymphoma is composed of small lymphocytes with plasmacytoid features(Morgen, Geddie et al. 2010). Amyloidosis may be seen.

The FNA features of metastatic malignancies vary depending on the primary organs and subtypes (Figure 7).

Approximately 3\% to 7\% of thyroid FNAs have conclusive features of malignancy, and most are papillary carcinomas(Yang, Schnadig et al. 2007; Cibas and Ali 2009). Postoperative risk of malignancy in thyroid nodules with malignant cytology averages $97 \%$ with a range from 93-100\%(Cibas and Ali 2009; Layfield, Cibas et al. 2010; Wang, Friedman et al. 2010). Of the differentiated cancers, papillary cancer comprises about $85 \%$ of cases, follicular carcinoma comprises about 10\%, and Hürthle cell carcinoma comprises 3\%(Hundahl, Fleming et al. 1998). Lobectomy for follicular carcinoma and Hürthle cell carcinoma and near total and 
total thyroidectomy for papillary thyroid carcinoma is recommended. Postoperative radioiodine (RAI) remnant ablation is increasingly being used to eliminate the postsurgical thyroid remnant(Hay, Thompson et al. 2002). Thyroidectomy is not usually used for metastatic tumors, non-Hodgkin lymphomas, and undifferentiated carcinomas(Cibas and Ali 2009)

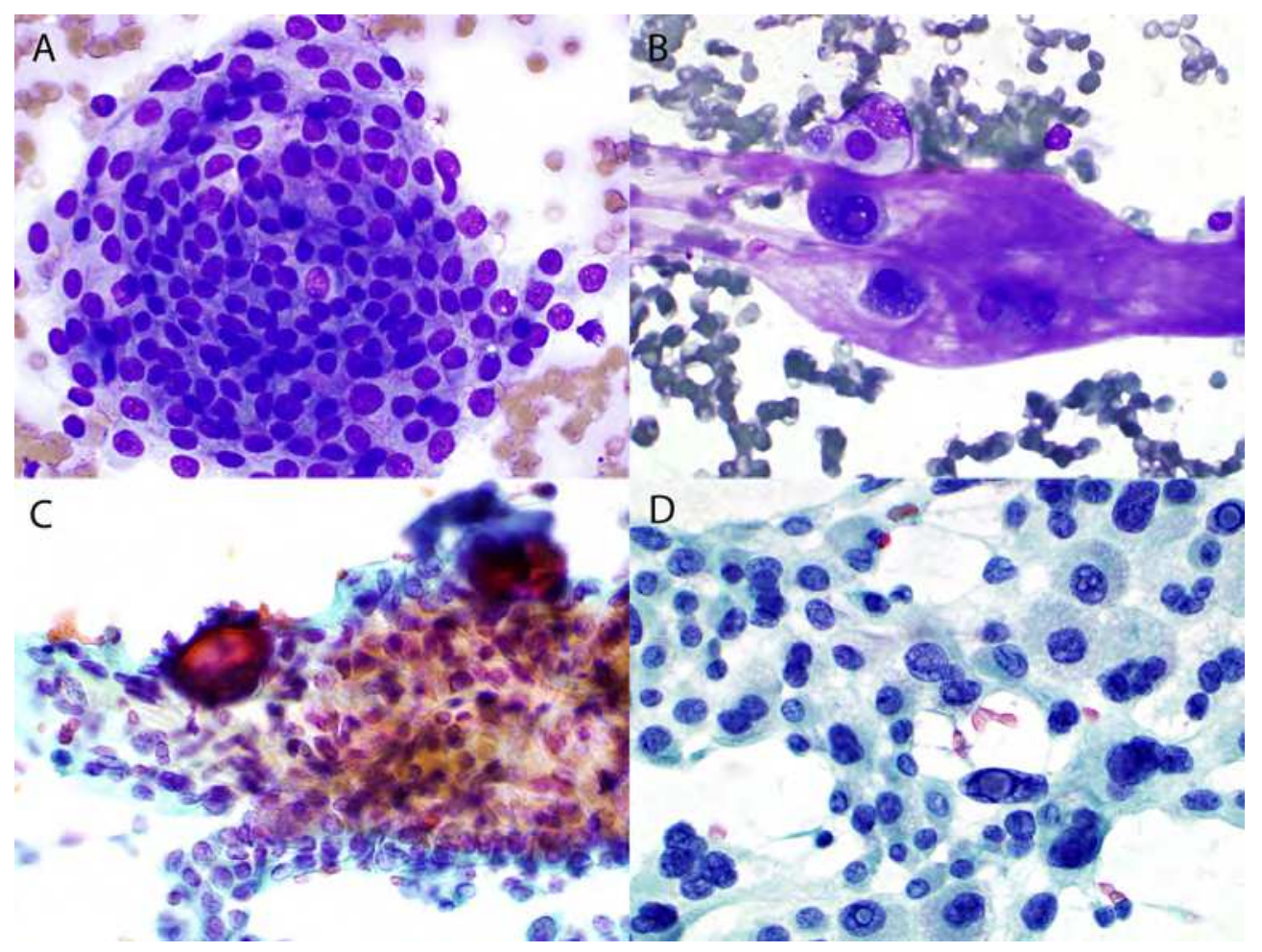

Fig. 4. Papillary thyroid carcinoma, FNA cytology, modified Giemsa (A and B) and Papanicolaou (C and D), 600x (A, B and D) and 400x (C). FNA smears show follicular cells arranged in true papillae with fibrovascular cores (C), swirling (A, papillary cap), singles (B) and cohesive clusters (D), with enlarged and elongated nuclei containing fine granular chromatin (powering), nuclear pseudoinclusion and nuclear grooves, and slightly dense cytoplasm (squamoid). Psammomatous calcification (C) and "chewing gum" dense colloid are seen $(\mathrm{B})$. 


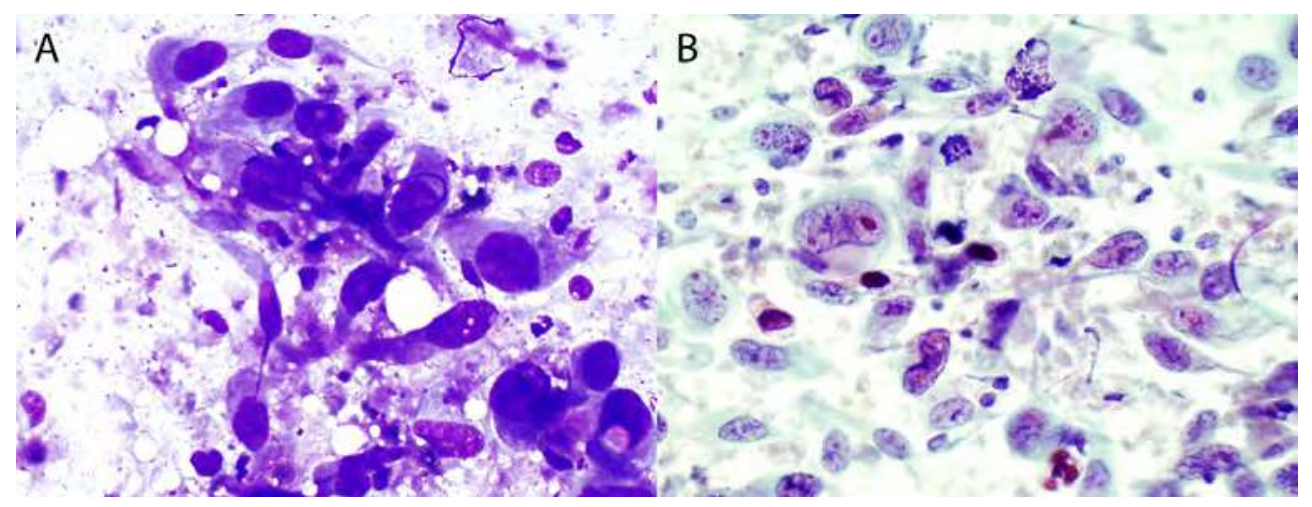

Fig. 5. Anaplastic thyroid carcinoma, FNA cytology, modifier Giemsa (A) and Papanicolaou stain (B), 600x. FNA smears show pleomorphic cells including bizarre spindle cells, atypical mitotic figure, and necrosis.

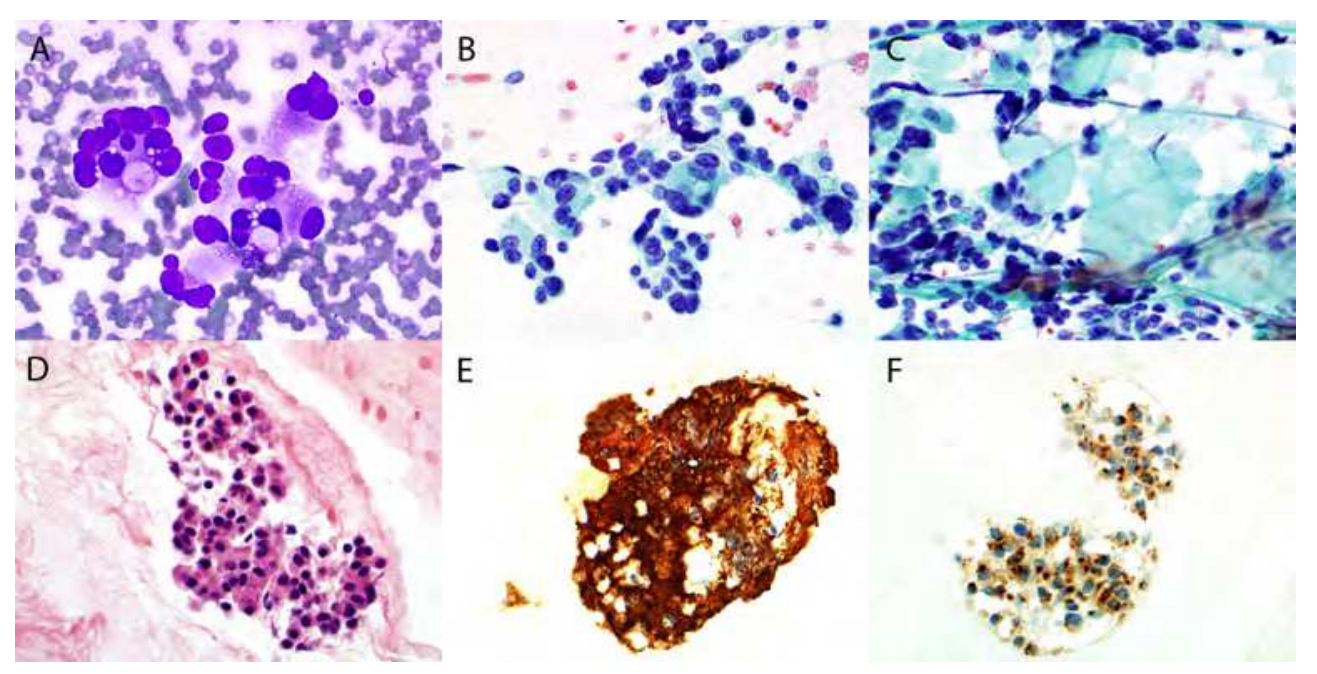

Fig. 6. Thyroid medullary carcinoma, FNA cytology. FNA smears (A: modified Giemsa stain, 600x; B and C: Papanicolaou stain, 600x) show pleomorphic epithelial cells that are present in loosely clusters and microacini/microfollicles, have round or oval nuclei containing granular and coarse ("salt and pepper") chromatin, some with prominent nucleoli, and scant to abundant cytoplasm, some with cytoplasmic granules. Amyloidosis is seen (C). Cellblock (D: H\&E stain, 400x) shows tumor cells that form microacini/microfollicles and have scant to abundant eosinophilic cytoplasm. The tumor cells are positive for Calcitonin (E: 400x) and chromogranin (F: 400x) identified by immunohistochemical stains, confirming the diagnosis. 




Fig. 7. Metastatic thymic carcinoma, FNA cytology. FNA smears (A: modified Giemsa stain, 600x and B: Papanicolaou stain, 600x) show cohesive three dimensional clusters of epithelial cells with round to oval nuclei containing prominent nucleoli, and scant cytoplasm.

Cellblock (C: H\&E stain, 600x) shows cohesive sheets of tumor cells with same cytomorphology as seen in FNA smears and surrounded by dense fibrous tissue. The tumor cells are positive for CD5 (D: 600x) and partially positive for CK7 (E: 600x), while are negative for thyroglobulin (F: 600x), calcitonin (G: 600x), and chromogranin (H: 600x), which confirms the diagnosis of thymic carcinoma, and exclude thymic neoplasm (follicular and medullary neoplasm), and parathyroid neoplasm.

2007 TBSRTC has been demonstrated to be excellent for reporting thyroid FNAs(Theoharis, Schofield et al. 2009). Each diagnostic category conveys specific risks of malignancy, which offers guidance for patient management. Routine second opinion review of indeterminate thyroid FNA biopsies can potentially obviate the need for diagnostic thyroidectomy in $25 \%$ of patients without increases in false negatives(Davidov, Trooskin et al. 2010). Routine second opinion review of FNA specimens increases sensitivity, specificity, positive predictive value, and negative predictive value(Tan, Kebebew et al. 2007).

\subsection{Immunohistochemistry used in thyroid lesions}

Immunohistochemical (IHC) stains are seldom used in thyroid FNA biopsy for follicular lesions. IHC can be performed on FNA cellblock or FNA smears.

Thyroid follicular neoplasms and medullary carcinomas are positive for TTF-1. Conventional papillary thyroid carcinoma is immunoreactive for p53 (76\%), galectin-3 (100\%), and EMA (50\%), while are negative for p63(Koo, Shin et al. 2010). Diffuse sclerosing variant of papillary carcinoma is immunohistochemically positive for p63 (28.6\%), p53 (42.9\%) galectin-3 (16.3\%), EMA (40.8\%)(Koo, Shin et al. 2010), and BCL-2(Koo, Shin et al. 2010). Medullary thyroid carcinoma is positive for calcitonin.

Immunohistochemical stains for CD3, CD20, CD79a, PAX-5, CD5, CD10, CD23, cyclin D1 (BCL-1), BCL-1, BCL-6, alpha or lambda light chain, and other lymphoid markers are useful for diagnosis of lymphoma(Morgen, Geddie et al. 2010). Aliquot of FNA aspiration should be sent for flow cytometry analysis.

\subsection{Molecular tests used in thyroid nodular lesions}

Molecular tests can be performed on FNA specimens and can help in diagnosis and classification of thyroid nodules(Chudova, Wilde et al. 2010). Many molecular markers (e.g., 
galectin-3(Bartolazzi, Orlandi et al. 2008; Kato and Fahey 2009), cytokeratin, BRAF(Lin, Liu et al. 2006; Pizzolanti, Russo et al. 2007; Sapio, Posca et al. 2007; Kato and Fahey 2009; Nikiforov, Steward et al. 2009), RAS(Nikiforov, Steward et al. 2009), RET/PTC(Pizzolanti, Russo et al. 2007; Sapio, Posca et al. 2007; Kato and Fahey 2009; Nikiforov, Steward et al. 2009), TRK(Sapio, Posca et al. 2007), Pax8-PPARү(Kato and Fahey 2009; Nikiforov, Steward et al. 2009), HBME-1(Kato and Fahey 2009), hTERT(Kato and Fahey 2009), miRNA(Kato and Fahey 2009), LOH at 10q23(Lin, Liu et al. 2006)) have been evaluated to improve diagnostic accuracy for indeterminate nodules(Sapio, Posca et al. 2007; Bartolazzi, Orlandi et al. 2008). Recent large prospective studies have confirmed the ability of genetic markers (BRAF, Ras, RET $=$ PTC) and protein markers (galectin-3) to improve preoperative diagnostic accuracy for patients with indeterminate thyroid nodules diagnosed by FNA biopsy(Pizzolanti, Russo et al. 2007; Sapio, Posca et al. 2007; Bartolazzi, Orlandi et al. 2008; Franco, Martinez et al. 2009; Nikiforov, Steward et al. 2009). It is likely that some combination of molecular markers will be used in the future to optimize management of patients with indeterminate cytology on FNA specimens. BRAF mutations occur in approximately $44 \%$ (from 29 to $83 \%$ of papillary carcinoma, and can be used in diagnosis and as a target of treatment(Lassalle, Hofman et al. 2010). With more and more basic and clinical translational research, molecular tests as an adjunctive diagnostic tool will increase the diagnostic accuracy of FNA biopsy with cytologic diagnoses of AUS/FLUS, follicular neoplasm/suspicious for follicular neoplasm, and suspicious for malignancy. However, molecular markers (Galectin-3, CITED1, HBME-1, Ras, RET/PTC, and PAX8/PPARY) have been identified in some histopathologically classified benign nodules(Arora, Scognamiglio et al. 2008). Follicular adenomas and Hürthle cell adenomas have similar gene expression profile as malignant tumors(Arora, Scognamiglio et al. 2008).

By detection of BRAF mutation and loss of heterozygosities $(\mathrm{LOH}), 66.7 \%$ papillary thyroid carcinomas (PTC), including $50 \%$ papillary microcarcinoma cases $(<1 \mathrm{~cm})$, were proved to be intrathyroid metastasis(Lin, Finkelstein et al. 2008). Patients with intrathyroid metastasis, including papillary microcarcinoma, had significantly increased lymph node metastasis(Lin, Finkelstein et al. 2008). LOHs of $17 q 21,17 p 13,10 q 23$ and $22 q 13$ may be important in predicting increased risk of lymph node metastasis(Lin, Finkelstein et al. 2008). LOH of 9p21 was found at the highest frequency in PTC (53.8\%), followed by 1p36 (46.2\%), 10q23 (34.6\%), and 22q13 (34.6\%)(Lin, Finkelstein et al. 2008). Papillary microcarcinoma had acquired similar genomic mutations as conventional PTC $(>1 \mathrm{~cm})$, but higher frequencies of mutations of B-RAF, 1p36, 18q, and 22q13 were found in the larger PTC, suggesting that they might play a role in the aggressiveness of PTC(Lin, Finkelstein et al. 2008). Different profiles of mutations were observed in conventional, follicular variant, and diffuse sclerosing variant of PTC, which might influence the different morphological appearances and clinical courses(Lin, Finkelstein et al. 2008). Therefore, molecular analysis can separate multifocal independent primary PTC from intrathyroid metastatic PTC, and may be more important than tumor size in predicting lymph node metastasis, aggressiveness, and prognosis of PTC(Lin, Finkelstein et al. 2008). Microarray analysis has be used in thyroid FNA specimens(Lubitz, Ugras et al. 2006).

\section{Clinical workup of parathyroid lesions}

\subsection{Introduction}

Primary hyperparathyroidism is a common problem encountered in clinical practice. Patients commonly present with elevated serum and urine calcium and parathyroid 
hormone (PTH) concentration. In most cases, the diagnosis is relatively straightforward. However, when imaging studies fail to localize the parathyroid adenoma or hyperplasia, management can be challenging.

The gold standard to determine the cause of primary hyperparathyroidism is bilateral neck exploration. Minimally invasive parathyroidectomy is the preferred treatment of choice, but it requires the accurate localization of a parathyroid lesion by ultrasound imaging, $\mathrm{Tc}^{99}$ sestamibi scan, and FNA combined with PTH test. Minimally invasive parathyroidectomy is not applicable in those patients who have coexisting thyroid cancers or nodules with suspicious cytology(Abraham, Duick et al. 2008) .

\subsection{Clinical workup of parathyroid lesions}

Ultrasound imaging and/or $\mathrm{Tc}^{99}$-sestamibi scan are used to localize the abnormal parathyroid glands. For the detection of the incidentalomas, the positive predictive value (PPV) of thyroid ultrasound was $21.4 \%$ (Kwak, Kim et al. 2009). In the overall patients, the sensitivity and PPV of ultrasound, Tc ${ }^{99}$-sestamibi scan, and ultrasound $+\mathrm{Tc}^{99}$-sestamibi scan to localize parathyroid adenoma are $96 \%$ and $91 \%, 92 \%$ and $87 \%$, and $95 \%$ and $94 \%$, respectively(Erbil, Salmaslioglu et al. 2007). FNA biopsy is seldom used in evaluation of parathyroid lesions, especially those that can be visualized by ultrasound. Some authors suggested that FNA is valuable in patients who have a nondiagnostic Tc ${ }^{99}$-sestamibi scan, with multiple enlarged parathyroid glands, prior failed surgery, differentiating parathyroid adenomas from posterior thyroid nodules, atypical location, and nonfunctioning parathyroid incidentalomas(Abraham, Duick et al. 2008; Vu and Erickson 2010). Cellular FNA specimens with features not typical for thyroid lesions should be triaged for PTH assay in the FNA rinse, which is useful to differentiate parathyroid lesions from thyroid lesions(Owens, Rekhtman et al. 2008; Ciuni, Ciuni et al. 2010; Lieu 2010). This technique is also used during operation(Lamont, McCarty et al. 2005).

\subsection{Fine needle aspiration biopsy of parathyroid lesions}

For the detection of the incidentalomas, the sensitivity of ultrasound guided FNA was $41.7 \%$, specificity was $97.7 \%$, accuracy was $85.7 \%$, PPV was $83.3 \%$, and negative predictive value (NPV) was $86 \%$ (Kwak, Kim et al. 2009). The sensitivity of FNA-parathyroid hormone test was $92.9 \%$, specificity was $100 \%$, accuracy was $94.4 \%$, PPV was $100 \%$, and NPV was $80 \%$ (Kwak, Kim et al. 2009). Overall, the sensitivity and positive predictive value of FNA$\mathrm{PTH}$ assay to localize parathyroid adenoma is higher compared with ultrasound, $\mathrm{Tc}^{99}$ sestamibi scan, and ultrasound + Tc ${ }^{99}$-sestamibi scan(Erbil, Salmaslioglu et al. 2007).

FNA aspirates of parathyroid lesions are often cellular(Absher, Truong et al. 2002; Owens, Rekhtman et al. 2008). FNA cytomorphologic features include small and monotonous to moderately anisokaryotic cells that are present in cohesive cellular disorganized sheets, cords, cohesive three-dimensional groups, papillary fragments, and microfollicles (in $90 \%$ of parathyroid adenomas and absence in parathyroid hyperplasia), have round to oval hyperchromatic nuclei containing finely to coarsely granular chromatin and inconspicuous nucleoli, and have fragile, pale blue or finely granular cytoplasm with ill-defined borders(Absher, Truong et al. 2002; Liu, Gnepp et al. 2004; Owens, Rekhtman et al. 2008) (Figure 8). Isolated cells and naked nuclei are commonly present and sometimes predominate(Absher, Truong et al. 2002; Liu, Gnepp et al. 2004; Owens, Rekhtman et al. 2008), and rare case shows lymphoid-like smears(Absher, Truong et al. 2002). Prominent 
nucleoli, mitotic figures, and karyolysis are seen in parathyroid carcinoma(Hara, Oyama et al. 1998). Nuclear pleomorphism is seen in $33 \%$ of parathyroid adenoma and absent in parathyroid hyperplasia(Liu, Gnepp et al. 2004). A granular smear background is usually present(Owens, Rekhtman et al. 2008). Oncocytic parathyroid adenoma is a rare benign neoplasm. It is challenging to distinguish from thyroid Hürthle cell lesion on FNA biopsy, and may be misinterpreted as suspicious for Hürthle cell neoplasm(Paker, Yilmazer et al. 2010) or Hürthle cell neoplasm. FNA reveals cellular smears containing monotonous oncocytic cells arranged in monolayered sheets, pseudopapillary structures and clusters within a rich vascular network(Paker, Yilmazer et al. 2010).



Fig. 8. Parathyroid adenoma, FNA cytology, modified Giemsa (A) and Papanicolaou stain (B), 600x. FNA smears show small and monotonous epithelial cells that are present in cohesive cellular disorganized sheets, three-dimensional groups and microfollicles, have round to oval hyperchromatic nuclei containing finely to coarsely granular chromatin and inconspicuous nucleoli, and have fragile, pale or finely granular cytoplasm with ill-defined borders.

Parathyroid cysts (PCS) are rare and rarely symptomatic except for swelling. PCS are divided into functional (hyperparathyroidism, hypercalcemia, and hypophosphatemia) and non-functional PCS that represent about $10 \%$ of PCS. The non-functional PCS are considered true PCS because their wall is lined by secretory epithelium, and the functioning PCS develop due to cystic degeneration of parathyroid gland adenomas. The ultrasound images demonstrate a cystic lesion. FNA aspirates clear liquid, which should be sent to chemistry laboratory to test PTH level(Absher, Truong et al. 2002; Ciuni, Ciuni et al. 2010; Lieu 2010). The first treatment is the aspiration FNA, which can be curative, but recurrences can be treated surgically(Ciuni, Ciuni et al. 2010).

FNA of parathyroid adenomas may cause severe fibrosis complicating surgery and final histologic diagnosis(Norman, Politz et al. 2007), which could be avoided by using fine bore needles (25 - 27 gauge) and fewer passes (1 to 2 passes)(Abraham, Duick et al. 2008). Needle track implantation of parathyroid carcinoma has been reported, although it is extremely rare(Agarwal, Dhingra et al. 2006). 


\subsection{Immunohistochemistry in parathyroid lesions}

IHC stains for PTH, synaptophysin, chromagranin, NSE, and CD56 can be performed on FNA smears and cellblock for confirmation of parathyroid origin.

The FNA cytomorphology of parathyroid adenoma shares some features with thyroid lesions, which may lead to misinterpretation as thyroid follicular lesion/neoplasm, medullary carcinoma, papillary carcinoma, and thyroid cyst(Absher, Truong et al. 2002; Owens, Rekhtman et al. 2008; Lieu 2010). Therefore, a PTH assay of needle rinse and IHC studies should be ordered for any case with an FNA cytomorphology that is not typical for thyroid lesion, PCS develop due to absence of colloid, and is a highly cellular specimen.

\section{Clinical workup of adrenal glands}

\subsection{Introduction}

Adrenal gland is the fourth most frequent site of spread of tumors after lungs, liver, and bone(Willis 1973; Lloyd, Kawashima et al. 2004). Metastatic malignancies are far more common than primary malignancies of the adrenal gland(Lloyd, Kawashima et al. 2004). Adrenal metastases develop in $27 \%$ of patients dying with carcinomas(Abrams, Spiro et al. 1950; Lloyd, Kawashima et al. 2004). The most common primary sites are the breast, lung, kidney, stomach, pancreas, ovary, and colon. Adrenal glands are also often involved by disseminated infectious diseases.

The commonly encountered primary adrenal neoplasms include myelolipoma $(2.5 \%$ of primary tumors)(Lam and Lo 2001), cortical adenoma (incidence, 1.5 - 7\%)(Stewart 2002), cortical carcinoma (incidence, 1/1 million/year)(Lloyd, Tischler et al. 2004), and pheochromocytoma. Eighty five percent of adrenal cortical adenomas are nonfunctional(Stewart 2002), while $80 \%$ of adrenal cortical carcinomas are functional(Lloyd, Tischler et al. 2004). Adrenal cortical carcinoma is also associated with Li-Fraumeni syndrome, Beckwith-Wiedemann syndrome, and Carney complex. Pheochromocytoma is generally associated with clinical symptoms due to overproduction of catecholamines, intermittent, paroxysmal hypertension accompanied by sweating, palpitations, headache, diaphoresis, nervousness, nausea, vomiting, weakness, abdominal or chest pain.

\subsection{Fine needle aspiration biopsy of adrenal lesions}

FNA is often used to evaluate nodular or mass lesions of adrenal glands under the guidance of CT scan, ultrasound, EUS, and MRI scan. Application of FNA biopsy for incidentally discovered adrenal masses (incidentaloma) is controversial(Nurnberg 2005; Lumachi, Borsato et al. 2007; Quayle, Spitler et al. 2007). A thorough clinical history and radiographic studies (CT scan, MRI and norcholesterol scintigraphy) are very important in the workup(Lumachi, Borsato et al. 2007). It may be difficult in some cases for FNA to distinguish benign (non-neoplastic or adenoma) from malignant adrenal cells with certainty(Tikkakoski, Taavitsainen et al. 1991), although a report stated that FNA cytology combined with clinical presentations (symptoms and endocrine function) and imaging studies (CT scan, MRI and norcholesterol scintigraphy) can increase diagnostic accuracy to 100\%(Lumachi, Borsato et al. 2007). In addition, other reports stated that image-guided FNA cytology is a safe and sensitive procedure and should be performed in all patients with incidentally discovered adrenal masses with high sensitivity $(83.3$ - 100\%), specificity (96.3 - 100\%), positive predictive value $(95.8$ - 100\%), negative predictive value $(100 \%)$, and accuracy (97.6\%)(Fassina, Borsato et al. 2000; Lumachi, Borsato et al. 2003). 
The characteristic FNA cytologic features of myelolipoma are the presence of normal bone marrow hematopoietic cells (megakaryocytes, myeloid cells, and erythrocytic precursors) and mature adipose tissue in variable proportions(Settakorn, Sirivanichai et al. 1999) (Figure 9). The differential diagnosis includes well-differentiated liposarcoma and hematopoietic tumors.

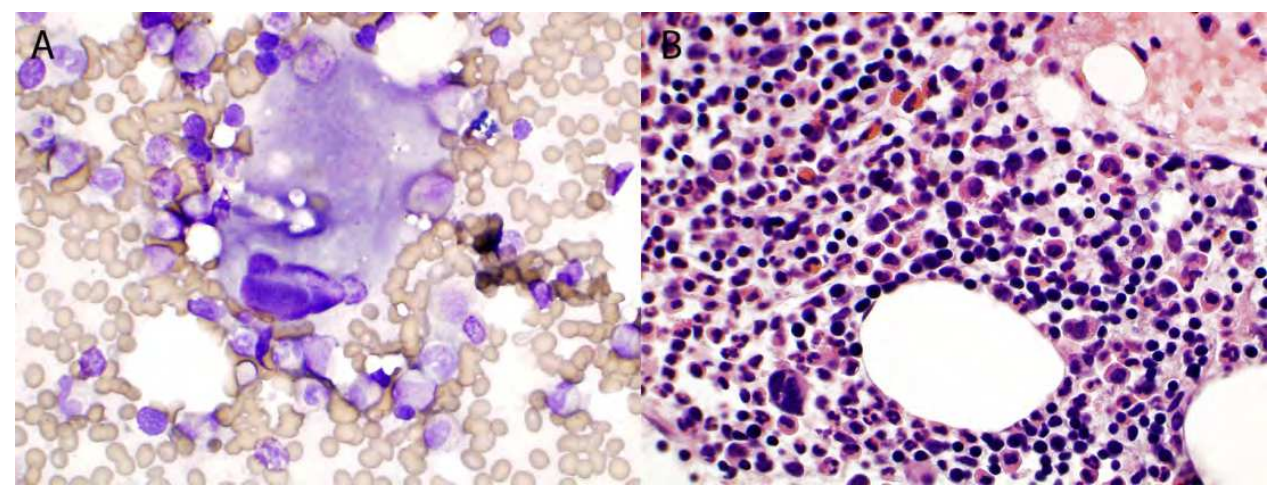

Fig. 9. Adrenal myelolipoma, FNA cytology. FNA smear (A: modified Giemsa stain, 600x) and cellblock (B: H\&E stain, 600x) show trilineage of hematopoietic cells, similar to the cells seen in normal bone marrow (megakaryocytes, myeloid cells and red blood cell precursors), adipocytes, and fat droplets.

The characteristic FNA cytologic features of adrenal cortical neoplasm (adenoma and carcinoma) are the presence of loose aggregates, fascicles or microacini of polygonal cells with uniform or pleomorphic, round or oval nuclei containing granular chromatin and distinct nucleoli, and moderate to abundant, clear, delicate, vacuolated or granular cytoplasm with indistinct cell borders(Fassina, Borsato et al. 2000; Stelow, Debol et al. 2005; Ren, Guo et al. 2006) (Figure 10). Abundant naked nuclei and intranuclear pseudoinclusions may be present. A foamy background of lipid droplets is always seen. The cells of adrenal cortical adenoma are smaller and less pleomorphic than carcinoma. Mitoses and necrosis are more frequently seen in carcinoma. Differential diagnosis includes non-neoplastic adrenal cortex, nodular hyperplasia, pheochromocytoma, metastatic renal cell carcinoma, hepatocellular carcinoma, and small blue cell tumor (when aggregates of naked nuclei are present).

FNA biopsy should be performed carefully in cases that are clinically suspicious for pheochromocytoma due to possible fatal hypertensive crisis or hemorrhage. Therefore, biochemical testing for pheochromocytoma should be performed before biopsy of adrenal masses. The characteristic FNA findings of pheochromocytoma are presence of bland to pleomorphic epithelioid or spindle cells present singly or in discohesive nests (zellballen) and acinar-microglandular structures or rosettes(Jimenez-Heffernan, Vicandi et al. 2006) (Figure 11). The tumor cells have single or multiple eccentrically-located (plasmacytoid), round to oval nuclei with prominent nucleoli and granular chromatin(Jimenez-Heffernan, Vicandi et al. 2006). Large intranuclear inclusions, binucleation or multinucleation, and naked nuclei are commonly seen(Jimenez-Heffernan, Vicandi et al. 2006). The cytoplasm is abundant, and delicate, granular or "squamoid" with ill-defined cell borders(JimenezHeffernan, Vicandi et al. 2006). Hyaline globules and rarely melanin pigment may be seen in 
the cytoplasm. Differential diagnosis includes adrenal cortical neoplasm, metastatic adenocarcinoma, melanoma and neuroendocrine neoplasms.

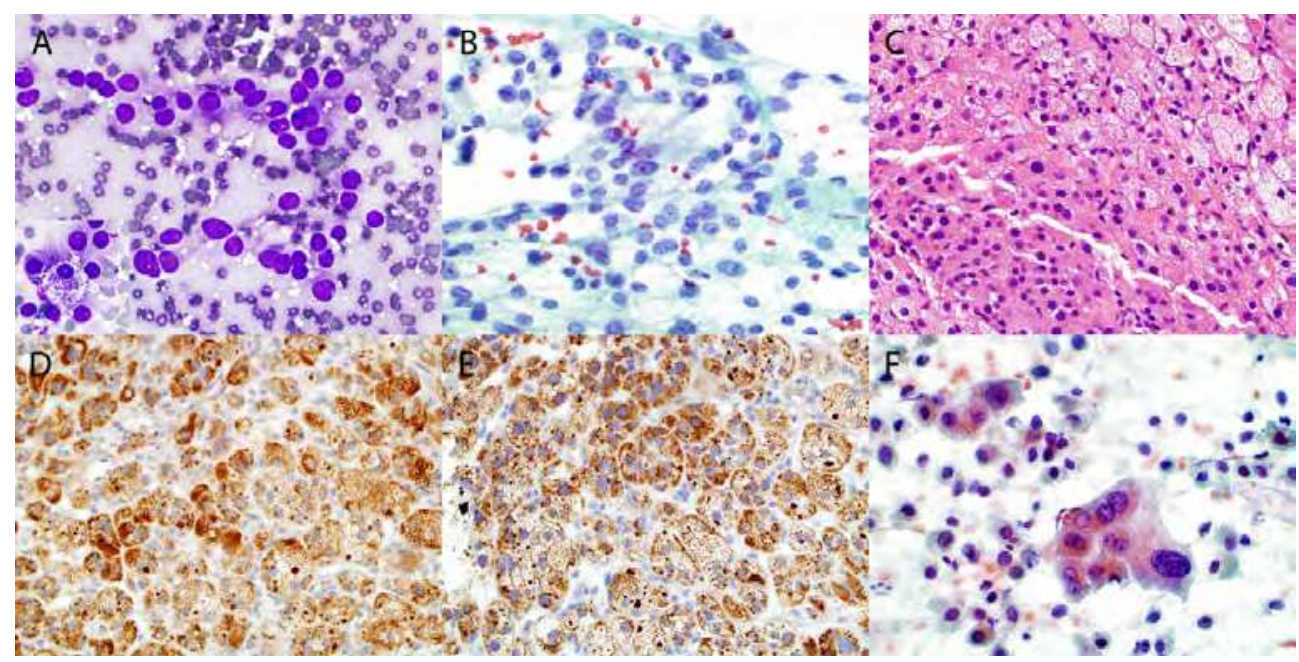

Fig. 10. Adrenal cortical neoplasms (adenoma, A to E, and carcinoma, F), FNA cytology. FNA smears (A: modified Giemsa stain, 600x; B: Papanicolaou stain, 600x) show loose aggregates or fascicles of polygonal cells with slightly pleomorphic, round or oval nuclei containing granular chromatin and distinct nucleoli, and moderate to abundant, clear, delicate, vacuolated or granular cytoplasm with indistinct cell borders. A foamy background of lipid droplets is seen. Cellblock (C: H\&E stain, 600x) shows the sheets of polygonal cells with either granular or vacuolated cytoplasm. The tumor cells are positive for S-100 (D, 600x) and inhibin (E, 600x). The cells of adrenal cortical carcinoma are larger and more pleomorphic than adenoma (F: FNA smear, Papanicolaou stain, 600x).

FNA is an important tool to diagnose adrenal metastases. FNA findings vary depending on the primary site of the metastatic malignancies. Comparison with morphology of the known primary malignancy should be performed. Immunohistochemical stains are very useful in narrowing the differential diagnosis. Adrenal tumors are positive for melan A and inhibin and negative for epithelial membrane antigen (EMA).

When FNA smears show abundant inflammatory cells, benign adrenal glandular epithelial cells, necrosis or granulomas, an infectious lesion should be considered. An aliquot of FNA should be sent for culture, or molecular tests, and special stains (GMS, PAS, AFB, FITE, and GRAM) should be ordered on cytospin, smear, or cellblock.

Complications of adrenal FNA biopsy include hypertension, hematoma of liver, thorax and duodenum(Quijano and Drut 1989), and pneumothorax(Lumachi, Borsato et al. 2007).

\subsection{Immunohistochemistry and special stains}

The following special and IHC stains are useful in primary adrenal lesions. Special stains (chloroacetate esterase, myeloid peroxidase) or immunostains (factor VIII) are helpful to confirm the myeloid nature of the immature cells in myelolipoma. Adrenal cortical nonneoplastic and neoplastic cells are positive for inhibin, A103 and melan A, while negative for 
CK7, CK20, and chromogranin. Pheochromocytoma cells are positive for chromogranin, synaptophysin and NSE, and are negative for EMA and cytokeratins. Sustentacular cells are positive for S-100.

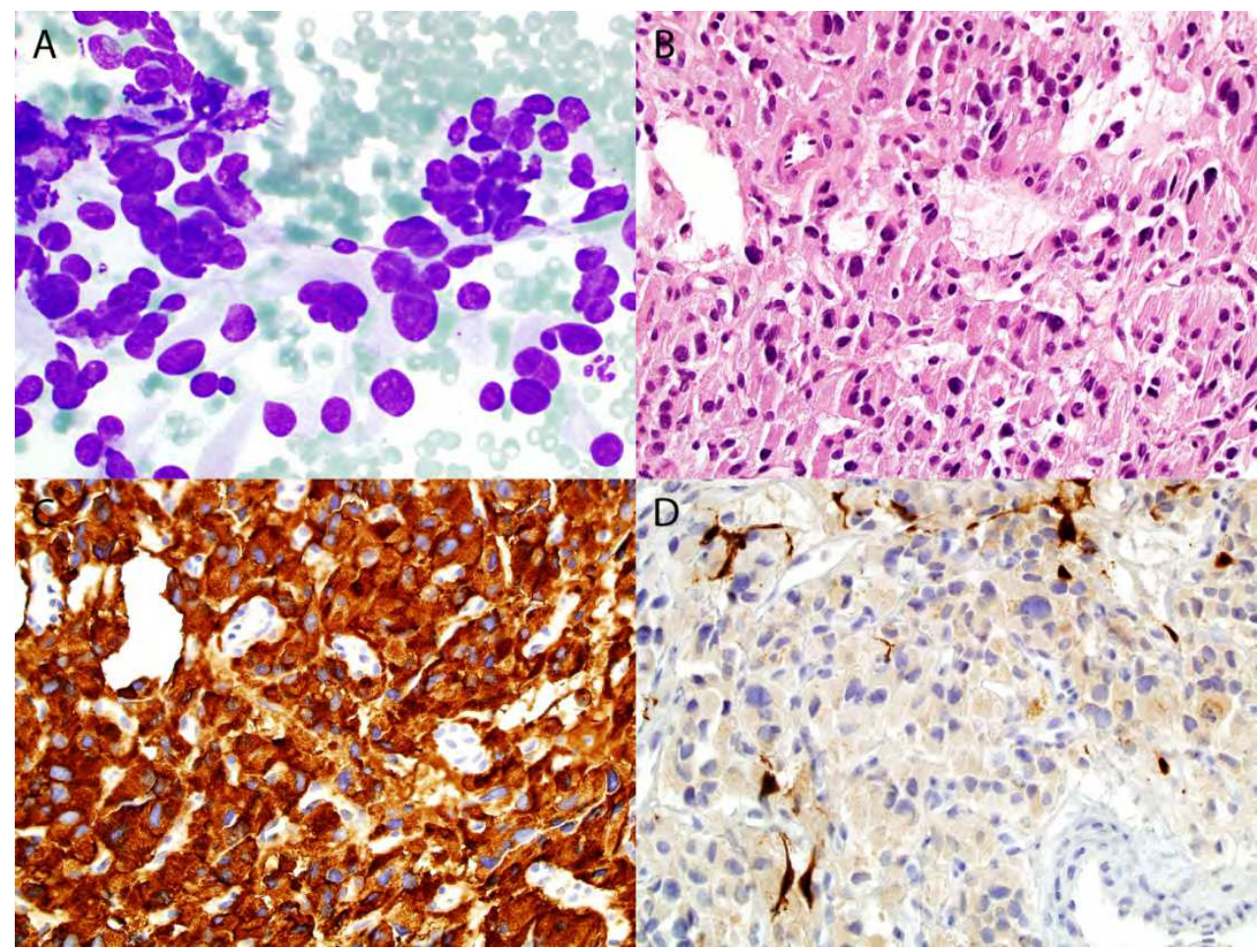

Fig. 11. Adrenal pheochromocytoma, FNA cytology. FNA smear shows pleomorphic epithelial cells present in loosely cohesive nests (zellballen), acinar/microglandular structures or rosettes. The tumor cells have single eccentrically-located (plasmacytoid), round to oval nuclei with prominent nucleoli and granular chromatin, naked nuclei, and abundant, delicate or granular cytoplasm with ill-defined cell borders. Cellblock (B: H\&E stained, 600x) shows nests of epithelial cells with abundant eosinophilic granular cytoplasm that surrounded by spindle cells and capillaries. Tumor cells are positive for chromogranin (C: 600x), and surrounded spindle cells (sustentacular cells) are positive for S-100 (D: 600x).

\section{Conclusion}

In summary, a nodule or mass found in the endocrine organs should be evaluated thoroughly, no matter with or without clinical symptoms. Based on clinical presentation, past medical history, imaging studies, and laboratory tests, clinicians should evaluate if further investigation by FNA or needle core biopsy with accessory studies (special stains, IHC or molecular studies) is valuable for accurate diagnosis and making decision of suitable therapy (follow-up, surgical excision, chemotherapy including targeted chemotherapy, or radiation). 


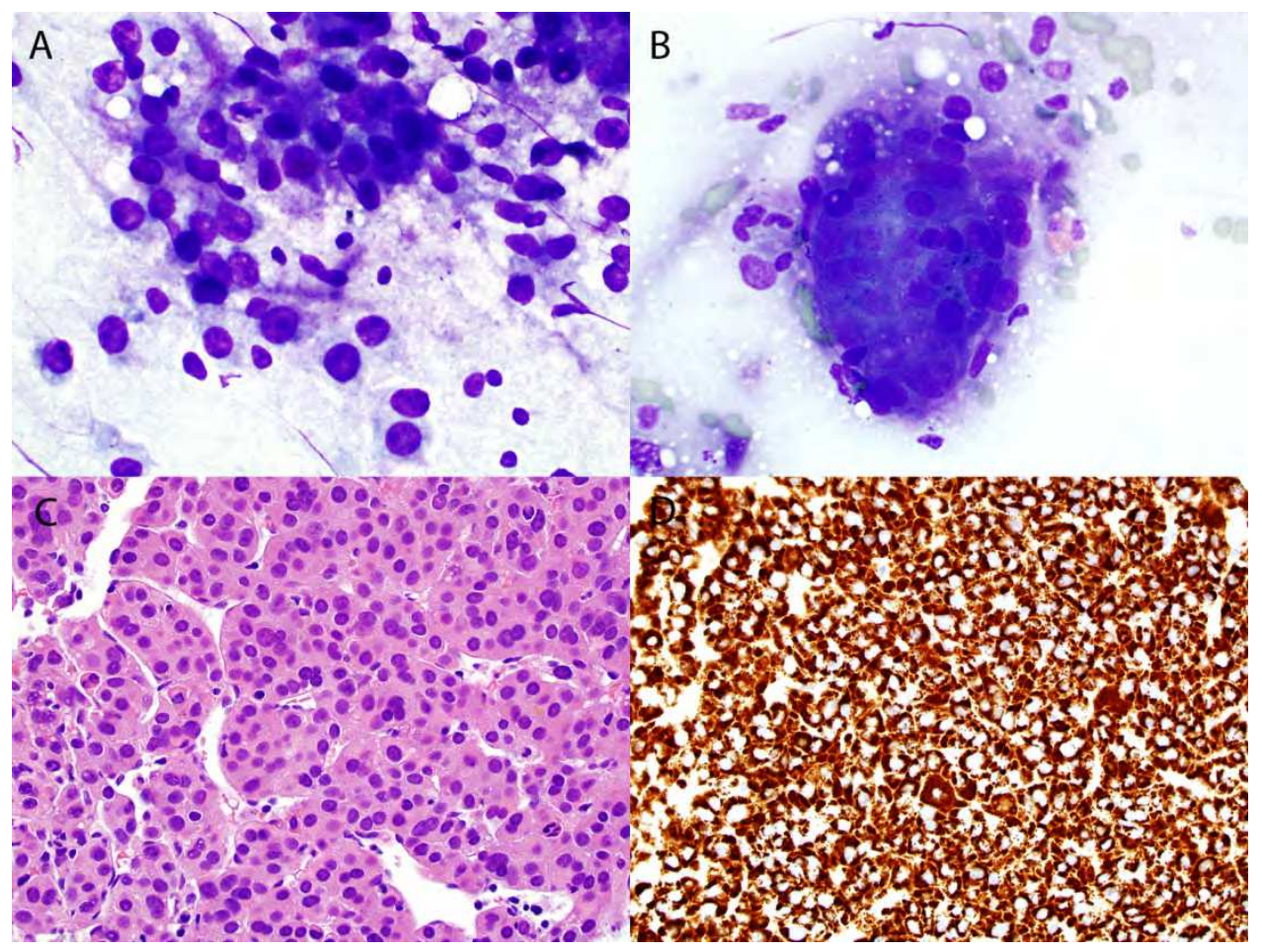

Fig. 12. Metastatic hepatocellular carcinoma to adrenal gland, FNA cytology. FNA smears (A and B, modified Giemsa stain, 600x) show loosely cohesive epithelial cells with round or oval hyperchromatic nuclei containing 1 to 3 prominent nucleoli and coarse chromatin, and fragile moderate granular cytoplasm (A), or cohesive 3 dimensional clusters of epithelial cells surrounded by endothelial cells of vessels (B). Cellblock (C: H\&E stain, 600x) shows thickened or pseudoglandular epithelial cells with moderate granular cytoplasm and surrounded by endothelial cells, typical histologic features of hepatocellular carcinoma. The tumor cells are positive for HepPar-1, a marker for hepatocytes and hepatocellular neoplasms (D: 600x). 


\section{References}

Abraham, D., D. S. Duick, et al. (2008). "Appropriate administration of fine-needle aspiration (FNA) biopsy on selective parathyroid adenomas is safe." Thyroid 18(5): 581-582; author reply 583-584.

Abrams, H. L., R. Spiro, et al. (1950). "Metastases in carcinoma; analysis of 1000 autopsied cases." Cancer 3(1): 74-85.

Absher, K. J., L. D. Truong, et al. (2002). "Parathyroid cytology: avoiding diagnostic pitfalls." Head Neck 24(2): 157-164.

Agarwal, G., S. Dhingra, et al. (2006). "Implantation of parathyroid carcinoma along fine needle aspiration track." Langenbecks Arch Surg 391(6): 623-626.

Are, C., J. F. Hsu, et al. (2007). "Histological aggressiveness of fluorodeoxyglucose positronemission tomogram (FDG-PET)-detected incidental thyroid carcinomas." Annals of surgical oncology 14(11): 3210-3215.

Arora, N., T. Scognamiglio, et al. (2008). "Do benign thyroid nodules have malignant potential? An evidence-based review." World J Surg 32(7): 1237-1246.

Bartolazzi, A., F. Orlandi, et al. (2008). "Galectin-3-expression analysis in the surgical selection of follicular thyroid nodules with indeterminate fine-needle aspiration cytology: a prospective multicentre study." The lancet oncology 9(6): 543-549.

Boelaert, K., J. Horacek, et al. (2006). "Serum thyrotropin concentration as a novel predictor of malignancy in thyroid nodules investigated by fine-needle aspiration." The Journal of clinical endocrinology and metabolism 91(11): 4295-4301.

Caruso, D. R. and E. L. Mazzaferri (1991). "Fine needle aspiration biopsy in the management of thyroid nodules." Endocrinologist 1(1): 194-202.

Chudova, D., J. I. Wilde, et al. (2010). "Molecular classification of thyroid nodules using high-dimensionality genomic data." J Clin Endocrinol Metab 95(12): 5296-5304.

Cibas, E. S. and S. Z. Ali (2009). "The Bethesda System for Reporting Thyroid Cytopathology." Thyroid 19(11): 1159-1165.

Ciuni, R., S. Ciuni, et al. (2010). "[Parathyroid cyst. Case report]." Annali italiani di chirurgia 81(1): 49-52.

Cooper, D. S., G. M. Doherty, et al. (2009). "Revised American Thyroid Association management guidelines for patients with thyroid nodules and differentiated thyroid cancer." Thyroid 19(11): 1167-1214.

Das, D. K., C. Janardan, et al. (2009). "Infarction in a thyroid nodule after fine needle aspiration: report of 2 cases with a discussion of the cause of pitfalls in the histopathologic diagnosis of papillary thyroid carcinoma." Acta cytologica 53(5): 571-575.

Davidov, T., S. Z. Trooskin, et al. (2010). "Routine second-opinion cytopathology review of thyroid fine needle aspiration biopsies reduces diagnostic thyroidectomy." Surgery 148(6): 1294-1299; discussion 1299-1301.

Donatini, G., T. Masoni, et al. (2010). "Acute respiratory distress following fine needle aspiration of thyroid nodule: case report and review of the literature." Il Giornale di chirurgia 31(8-9): 387-389. 
Erbil, Y., A. Salmaslioglu, et al. (2007). "Use of preoperative parathyroid fine-needle aspiration and parathormone assay in the primary hyperparathyroidism with concomitant thyroid nodules." Am J Surg 193(6): 665-671.

Fassina, A. S., S. Borsato, et al. (2000). "Fine needle aspiration cytology (FNAC) of adrenal masses." Cytopathology : official journal of the British Society for Clinical Cytology 11(5): 302-311.

Franco, C., V. Martinez, et al. (2009). "Molecular markers in thyroid fine-needle aspiration biopsy: a prospective study." Applied immunohistochemistry \& molecular morphology : AIMM / official publication of the Society for Applied Immunohistochemistry 17(3): 211-215.

Giorgadze, T., E. D. Rossi, et al. (2004). "Does the fine-needle aspiration diagnosis of "Hurthle-cell neoplasm/follicular neoplasm with oncocytic features" denote increased risk of malignancy?" Diagn Cytopathol 31(5): 307-312.

Grant, C. S., I. D. Hay, et al. (1989). "Long-term follow-up of patients with benign thyroid fine-needle aspiration cytologic diagnoses." Surgery 106(6): 980-985; discussion 985986.

Haider, A. S., E. A. Rakha, et al. (2011). "The impact of using defined criteria for adequacy of fine needle aspiration cytology of the thyroid in routine practice." Diagn Cytopathol 39(2): 81-86.

Hamberger, B., H. Gharib, et al. (1982). "Fine-needle aspiration biopsy of thyroid nodules. Impact on thyroid practice and cost of care." Am J Med 73(3): 381-384.

Hara, H., T. Oyama, et al. (1998). "Cytologic characteristics of parathyroid carcinoma: a case report." Diagn Cytopathol 18(3): 192-198.

Harach, H. R., K. O. Franssila, et al. (1985). "Occult papillary carcinoma of the thyroid. A "normal" finding in Finland. A systematic autopsy study." Cancer 56(3): 531538.

Hay, I. D., G. B. Thompson, et al. (2002). "Papillary thyroid carcinoma managed at the Mayo Clinic during six decades (1940-1999): temporal trends in initial therapy and longterm outcome in 2444 consecutively treated patients." World journal of surgery 26(8): 879-885.

Hegedus, L. (2004). "Clinical practice. The thyroid nodule." The New England journal of medicine 351(17): 1764-1771.

Hundahl, S. A., I. D. Fleming, et al. (1998). "A National Cancer Data Base report on 53,856 cases of thyroid carcinoma treated in the U.S., 1985-1995 [see commetns]." Cancer 83(12): 2638-2648.

Jemal, A., R. Siegel, et al. (2010). "Cancer statistics, 2010." CA: a cancer journal for clinicians 60(5): 277-300.

Jimenez-Heffernan, J. A., B. Vicandi, et al. (2006). "Cytologic features of pheochromocytoma and retroperitoneal paraganglioma: a morphologic and immunohistochemical study of 13 cases." Acta Cytol 50(4): 372-378.

Kato, M. A. and T. J. Fahey, 3rd (2009). "Molecular markers in thyroid cancer diagnostics." The Surgical clinics of North America 89(5): 1139-1155.

Koo, J. S., E. Shin, et al. (2010). "Immunohistochemical characteristics of diffuse sclerosing variant of papillary carcinoma: comparison with conventional papillary 
carcinoma." APMIS : acta pathologica, microbiologica, et immunologica Scandinavica 118(10): 744-752.

Kwak, J. Y., E. K. Kim, et al. (2009). "Parathyroid incidentalomas detected on routine ultrasound-directed fine-needle aspiration biopsy in patients referred for thyroid nodules and the role of parathyroid hormone analysis in the samples." Thyroid 19(7): 743-748.

Lam, K. Y. and C. Y. Lo (2001). "Adrenal lipomatous tumours: a 30 year clinicopathological experience at a single institution." Journal of clinical pathology 54(9): 707-712.

Lamont, J. P., T. M. McCarty, et al. (2005). "Validation study of intraoperative fine-needle aspiration of parathyroid tissue with measurement of parathyroid hormone levels using the rapid intraoperative assay." Proceedings 18(3): 214-216.

Lassalle, S., V. Hofman, et al. (2010). "Clinical impact of the detection of BRAF mutations in thyroid pathology: potential usefulness as diagnostic, prognostic and theragnostic applications." Current medicinal chemistry 17(17): 1839-1850.

Layfield, L. J., J. Abrams, et al. (2008). "Post-thyroid FNA testing and treatment options: a synopsis of the National Cancer Institute Thyroid Fine Needle Aspiration State of the Science Conference." Diagn Cytopathol 36(6): 442-448.

Layfield, L. J., E. S. Cibas, et al. (2010). "Thyroid fine needle aspiration cytology: a review of the National Cancer Institute state of the science symposium." Cytopathology : official journal of the British Society for Clinical Cytology 21(2): 75-85.

Lewis, C. M., K. P. Chang, et al. (2009). "Thyroid fine-needle aspiration biopsy: variability in reporting." Thyroid 19(7): 717-723.

Lieu, D. (2010). "Cytopathologist-performed ultrasound-guided fine-needle aspiration of parathyroid lesions." Diagn Cytopathol 38(5): 327-332.

Lin, X., S. D. Finkelstein, et al. (2008). "Molecular analysis of multifocal papillary thyroid carcinoma." Journal of molecular endocrinology 41(4): 195-203.

Lin, X., Y. Liu, et al. (2006). "B-RAF and 10q23 loss of heterozygosity are valuable diagnostic molecular markers of follicular variant of papillary thyroid carcinoma in thyroid fine needle aspiration cytology initially classified as follicular lesion." Modern Pathology 19(supplement 1): 64A.

Liu, F., D. R. Gnepp, et al. (2004). "Fine needle aspiration of parathyroid lesions." Acta cytologica 48(2): 133-136.

Lloyd, R. V., A. Kawashima, et al. (2004). Secondary tumors. World Health Organization Classification of Tumors: Pathology \& Genetics: Tumors of Endocrine Organs. R. A. DeLellis, R. V. Lloyd, P. U. Heitz and C. Eng. Lyon, IARC Press: 172-173.

Lloyd, R. V., A. S. Tischler, et al. (2004). Adrenal tumors: Introduction. World Health Organization Classification of tumors: Pathology \& Genetics: Tumors of Endocrine Organs. R. A. DeLellis, R. V. Lloyd, P. U. Heitz and C. Eng. Lyon, IARC Press: 137138.

Lubitz, C. C., S. K. Ugras, et al. (2006). "Microarray analysis of thyroid nodule fine-needle aspirates accurately classifies benign and malignant lesions." J Mol Diagn 8(4): 490498; quiz 528. 
Lumachi, F., S. Borsato, et al. (2003). "CT-scan, MRI and image-guided FNA cytology of incidental adrenal masses." European journal of surgical oncology : the journal of the European Society of Surgical Oncology and the British Association of Surgical Oncology 29(8): 689-692.

Lumachi, F., S. Borsato, et al. (2007). "High risk of malignancy in patients with incidentally discovered adrenal masses: accuracy of adrenal imaging and image-guided fineneedle aspiration cytology." Tumori 93(3): 269-274.

Mazzaferri, E. L. (1993). "Management of a solitary thyroid nodule." The New England journal of medicine 328(8): 553-559.

Mihai, R., A. J. Parker, et al. (2009). "One in four patients with follicular thyroid cytology (THY3) has a thyroid carcinoma." Thyroid : official journal of the American Thyroid Association 19(1): 33-37.

Morgen, E. K., W. Geddie, et al. (2010). "The role of fine-needle aspiration in the diagnosis of thyroid lymphoma: a retrospective study of nine cases and review of published series." Journal of clinical pathology 63(2): 129-133.

Nikiforov, Y. E., D. L. Steward, et al. (2009). "Molecular testing for mutations in improving the fine-needle aspiration diagnosis of thyroid nodules." The Journal of clinical endocrinology and metabolism 94(6): 2092-2098.

Norman, J., D. Politz, et al. (2007). "Diagnostic aspiration of parathyroid adenomas causes severe fibrosis complicating surgery and final histologic diagnosis." Thyroid 17(12): 1251-1255.

Nurnberg, D. (2005). "[Ultrasound of adrenal gland tumours and indications for fine needle biopsy (uFNB)]." Ultraschall in der Medizin 26(6): 458-469.

Owens, C. L., N. Rekhtman, et al. (2008). "Parathyroid hormone assay in fine-needle aspirate is useful in differentiating inadvertently sampled parathyroid tissue from thyroid lesions." Diagnostic cytopathology 36(4): 227-231.

Paker, I., D. Yilmazer, et al. (2010). "Intrathyroidal oncocytic parathyroid adenoma: a diagnostic pitfall on fine-needle aspiration." Diagn Cytopathol 38(11): 833-836.

Pizzolanti, G., L. Russo, et al. (2007). "Fine-needle aspiration molecular analysis for the diagnosis of papillary thyroid carcinoma through BRAF V600E mutation and RET/PTC rearrangement." Thyroid : official journal of the American Thyroid Association 17(11): 1109-1115.

Pu, R. T., J. Yang, et al. (2006). "Does Hurthle cell lesion/neoplasm predict malignancy more than follicular lesion/neoplasm on thyroid fine-needle aspiration?" Diagn Cytopathol 34(5): 330-334.

Quayle, F. J., J. A. Spitler, et al. (2007). "Needle biopsy of incidentally discovered adrenal masses is rarely informative and potentially hazardous." Surgery 142(4): 497-502; discussion 502-494.

Quijano, G. and R. Drut (1989). "Cytologic characteristics of Wilms' tumors in fine needle aspirates. A study of ten cases." Acta cytologica 33(2): 263-266.

Ren, R., M. Guo, et al. (2006). "Fine-needle aspiration of adrenal cortical carcinoma: cytologic spectrum and diagnostic challenges." Am J Clin Pathol 126(3): 389-398.

Renshaw, A. A. (2001). "Accuracy of thyroid fine-needle aspiration using receiver operator characteristic curves." Am J Clin Pathol 116(4): 477-482. 
Renshaw, A. A. and N. Pinnar (2007). "Comparison of thyroid fine-needle aspiration and core needle biopsy." Am J Clin Pathol 128(3): 370-374.

Sapio, M. R., D. Posca, et al. (2007). "Detection of RET/PTC, TRK and BRAF mutations in preoperative diagnosis of thyroid nodules with indeterminate cytological findings." Clinical endocrinology 66(5): 678-683.

Settakorn, J., C. Sirivanichai, et al. (1999). "Fine-needle aspiration cytology of adrenal myelolipoma: case report and review of the literature." Diagnostic cytopathology 21(6): 409-412.

Stelow, E. B., S. M. Debol, et al. (2005). "Sampling of the adrenal glands by endoscopic ultrasound-guided fine-needle aspiration." Diagn Cytopathol 33(1): 26-30.

Stewart, P. M. (2002). The adrenal cortex. Williams Textbook of Endocrinology. P. R. Larsen, H. M. Kronenberg, s. Melmed and K. S. Polonsky. Philadelphia, Saunders: 491-551.

Tan, G. H. and H. Gharib (1997). "Thyroid incidentalomas: management approaches to nonpalpable nodules discovered incidentally on thyroid imaging." Annals of internal medicine 126(3): 226-231.

Tan, Y. Y., E. Kebebew, et al. (2007). "Does routine consultation of thyroid fine-needle aspiration cytology change surgical management?" J Am Coll Surg 205(1): 8-12.

Tee, Y. Y., A. J. Lowe, et al. (2007). "Fine-needle aspiration may miss a third of all malignancy in palpable thyroid nodules: a comprehensive literature review." Ann Surg 246(5): 714-720.

Theoharis, C. G., K. M. Schofield, et al. (2009). "The Bethesda thyroid fine-needle aspiration classification system: year 1 at an academic institution." Thyroid : official journal of the American Thyroid Association 19(11): 1215-1223.

Tikkakoski, T., M. Taavitsainen, et al. (1991). "Accuracy of adrenal biopsy guided by ultrasound and CT." Acta radiologica 32(5): 371-374.

Tunbridge, W. M., D. C. Evered, et al. (1977). "The spectrum of thyroid disease in a community: the Whickham survey." Clinical endocrinology 7(6): 481-493.

Vander, J. B., E. A. Gaston, et al. (1968). "The significance of nontoxic thyroid nodules. Final report of a 15-year study of the incidence of thyroid malignancy." Annals of internal medicine 69(3): 537-540.

Vu, D. H. and R. A. Erickson (2010). "Endoscopic ultrasound-guided fine-needle aspiration with aspirate assay to diagnose suspected mediastinal parathyroid adenomas." Endocrine practice : official journal of the American College of Endocrinology and the American Association of Clinical Endocrinologists 16(3): 437-440.

Wang, C. C., L. Friedman, et al. (2010). "A Large Multicenter Correlation Study of Thyroid Nodule Cytopathology and Histopathology." Thyroid : official journal of the American Thyroid Association.

Willis, R. V. (1973). The Spread of Tumors in the Human Body. London, Butterworth.

Wu, H. H., J. Clouse, et al. (2008). "Fine-needle aspiration cytology of Hurthle cell carcinoma of the thyroid." Diagn Cytopathol 36(3): 149-154.

Yang, J., V. Schnadig, et al. (2007). "Fine-needle aspiration of thyroid nodules: a study of 4703 patients with histologic and clinical correlations." Cancer 111(5): 306-315. 
Yassa, L., E. S. Cibas, et al. (2007). "Long-term assessment of a multidisciplinary approach to thyroid nodule diagnostic evaluation." Cancer 111(6): 508-516. 


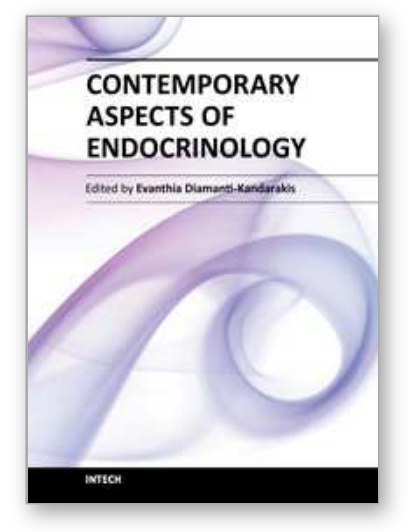

\author{
Contemporary Aspects of Endocrinology \\ Edited by Dr. Evanthia Diamanti-Kandarakis
}

ISBN 978-953-307-357-6

Hard cover, 454 pages

Publisher InTech

Published online 30, November, 2011

Published in print edition November, 2011

This book aims to provide readers with a general as well as an advanced overview of the key trends in endocrine disorders. While covering a variety of topics ranging from thyroid carcinogenesis and pituitary adenomas to adrenal tumors and metabolic bone disease, this book also focuses on more specific issues not yet fully elucidated (e.g. the molecular pathways involved in thyrotropin beta gene regulation or monogenic phosphate balance disorders). Readers of different fields and background will have the opportunity to update their knowledge and more importantly to clarify areas of uncertainty and controversies in several topics of endocrine disorders.

\title{
How to reference
}

In order to correctly reference this scholarly work, feel free to copy and paste the following:

Xiaoqi Lin and Bing Zhu (2011). Clinical Workup of Nodular and Mass Lesions of the Endocrine Organs, Contemporary Aspects of Endocrinology, Dr. Evanthia Diamanti-Kandarakis (Ed.), ISBN: 978-953-307-357-6, InTech, Available from: http://www.intechopen.com/books/contemporary-aspects-of-endocrinology/clinicalworkup-of-nodular-and-mass-lesions-of-the-endocrine-organs

\section{INTECH}

open science | open minds

\section{InTech Europe}

University Campus STeP Ri

Slavka Krautzeka 83/A

51000 Rijeka, Croatia

Phone: +385 (51) 770447

Fax: +385 (51) 686166

www.intechopen.com

\section{InTech China}

Unit 405, Office Block, Hotel Equatorial Shanghai

No.65, Yan An Road (West), Shanghai, 200040, China

中国上海市延安西路65号上海国际贵都大饭店办公楼 405 单元

Phone: +86-21-62489820

Fax: $+86-21-62489821$ 
(C) 2011 The Author(s). Licensee IntechOpen. This is an open access article distributed under the terms of the Creative Commons Attribution 3.0 License, which permits unrestricted use, distribution, and reproduction in any medium, provided the original work is properly cited. 